\title{
SOBRE O TAGARELAR FEMININO: DE WALTER BENJAMIN A JACQUES LACAN
}

Isabela Ferreira de Pinho

\section{RESUMO}

O presente artigo tem em vista possíveis aproximações entre Walter Benjamin e Jacques Lacan a partir da noção de um tagarelar feminino encontrado na obra de ambos os autores. Minha hipótese é de que em ambos a linguagem feminina constitui uma experiência de imediatidade da língua em que a oposição indizível/dizível não se dá. Para pensar essa experiência ambos os autores recorrem à imagem de um cristal da língua, de sua autotransparência, para a qual os chistes e homófonos apontam.

Palavras-chave: Tagarelar. Lalangue. Linguagem. Benjamin. Lacan.

\section{ABOUT FEMININE CHATTER: FROM WALTER BENJAMIN TO JACQUES LACAN}

\begin{abstract}
This article aims at unpacking possible relationships between Walter Benjamin and Jacques Lacan starting from the notion of a feminine chatter that appears in both authors' oeuvre. My hypothesis is that the feminine chatter presents an experience of the immediacy of language in which the opposition between unspeakable/speakable is no longer possible. In order to grasp that experience, both Benjamin and Lacan speak of a crystalline and transparent language of which slips and homophones are examples.
\end{abstract}

Keywords: Chatter. Lalangue. Language. Benjamin. Lacan. 
Podemos dizer que não há muitas pesquisas acerca de possíveis aproximações entre Walter Benjamin e Jacques Lacan. Como sugere Cláudio Oliveira no artigo "Língua pura e alíngua: um encontro (im)possível entre Benjamin e Lacan" (OLIVEIRA, 2016, 41-50), tudo acontece como se leitores de Benjamin não lessem Lacan, e leitores de Lacan não lessem Benjamin. Dentre os poucos trabalhos que encontrei até o presente momento, podemos dar destaque para os livros Benjamin-Lacan, do discurso do Outro (1998) de Gregor Schwering (1998) e O Real da perspectiva, o Barroco, a Psicanálise lacaniana e o cadáver na cultura (2013), de Sebastian Kirsch, (KIRSCH, 2013) ainda não traduzidos para a língua portuguesa. $O$ presente artigo se dedica a esse "silêncio".

O ponto de encontro entre Benjamin e Lacan que move esse artigo talvez possa parecer ainda mais insólito. Trata-se de um tema, uma questão: o feminino. Na verdade, minha ida a Lacan passa por uma proposta feita por Benjamin, uma indagação acerca do que seria uma cultura do feminino e, sobretudo, uma linguagem feminina. Essa indagação surge em um ensaio de juventude ainda não traduzido para o português, intitulado "Metafísica da juventude", escrito entre 1913 e 1914. Esse ensaio deve ser compreendido na esteira das críticas do movimento de juventude (Jugendbewegung) a uma certa concepção de história e linguagem, e ao sistema educacional vigente nos anos juvenis de Benjamin.

Podemos pensar, então, em duas principais fontes históricas para a redação da "Metafísica da Juventude", às quais me dediquei em minha dissertação de mestrado, e que por ora, não poderei abordar, mas somente nomear. A primeira seria Gustav Wyneken, fundador da Freie Schulgemeinde, de quem Benjamin foi aluno em 1906. Benjamin foi um dos principais responsáveis por levar o movimento de juventude e as reformas propostas por Wyneken para a universidade. A segunda seria o curso de verão ministrado pelo neokantiano Heinrich Rickert na universidade de Friburgo em que este 
pensava em "masculino" e "feminino" como esferas axiológicas de seu "Sistema de Valores" (1913). ${ }^{1}$

Importante para nós é o fato de que a crítica à história como herança, como acúmulo de meros fatos históricos isolados, diante dos quais nos encontramos como meros receptores, coincide com a crítica a uma língua comunicativa, instrumentalizada, ambas representadas pela tradição paterna, ou pelo "ser dos pais" (Sein der Väter), como diz Benjamin. Por isso, feminino e juventude constituem elementos para a crítica da cultura desses anos juvenis de Benjamin, como podemos constatar em uma carta ao amigo do movimento de juventude, Herbert Belmore, datada de 23 de junho de 1913, em que Benjamin questiona:

Quem sabe até onde se estende a natureza profunda da mulher? O que sabemos nós da mulher? Tão pouco quanto da juventude. Nós somos ainda sem experiência de uma cultura da mulher, assim como nós ignoramos uma cultura da juventude (BENJAMIN, 1979, p. 61).

Na mesma carta a Belmore, Benjamin esclarece:

eu, a bem dizer, evito aqui toda linguagem concreta e falo de bom grado em masculino e feminino: não estão eles extremamente misturados no ser humano?! E dessa forma você compreende que em uma reflexão sobre a cultura eu estimo um pouco primária a tipologia "homem", "mulher" (BENJAMIN, 1979, p. 61).

Considero importante a distinção que Benjamin produz, nos trechos supracitados, entre uma cultura feminina e uma cultura de mulheres empíricas. Em certo sentido, "mulher" e "juventude" aparecem como metáforas para outra concepção de história, de tempo e de linguagem. Mas gostaria de me concentrar, sobretudo, na questão da linguagem feminina suscitada no ensaio. Se por um lado, na "Metafísica da juventude", Benjamin concebe a linguagem masculina como uma infatigável dialética, as personagens Safo, a mulher e a prostituta, em suas atitudes tipificadas de mulheres silenciosas, aparecem, por outro lado, como porta-vozes de um passado feminino da linguagem (Weiblich-

1 Cf. PINHO, Isabela Ferreira de. O feminino como Medium da linguagem: sobre algumas figuras femininas na obra de Walter Benjamin. 2014. 141 f. Dissertação (mestrado em Filosofia) - Programa de Pós-graduação em Filosofia, UFF, Niterói, 2014.

Doutoranda em Filosofia pela UFRJ. Brasileira, residente em Rio de Janeiro-RJ. E-mail: isabelafpinho@gmail.com 
Gewesenes im Gespräch), inacessível ao presente do falante. Sobretudo, a linguagem das personagens femininas não é da ordem de um meio para um fim, uma linguagem comunicativa, mas consiste em um louco tagarelar. Ao se perguntar como Safo e suas alunas conversavam, Benjamin afirma que elas não depositam confiança na linguagem como comunicação (Mitteilung), mas que levam a sério o prazer lúdico da conversa. Por isso, ele dirá que "elas caem em conversa inútil, tagarelam [sie werden geschwätzig]" (BENJAMIN, 1991, 95). Em busca do que seria esse tagarelar, ele afirma que "as mulheres falantes são possuídas por uma língua louca [sprechende frauen sind von einer wahnwitzgen Sprache besessen]" (BENJAMIN, 1991, p. 95). Em alemão, Benjamin utiliza a palavra "wahnwitzigen" para o adjetivo "louca". Nesse vocábulo, encontramos o substantivo "Wahn", que significa delírio, frenesi, ilusão, e o adjetivo, "witzig", "espirituoso (a)", mas cuja origem é o "Witz", chiste ou ato falho, termo caro ao primeiro romantismo alemão e também à Psicanálise, de Freud a Lacan. É a partir dessa indicação que procurarei, mais à frente, delinear possíveis aproximações entre Benjamin e Lacan.

Em primeiro lugar é preciso pensar os deslocamentos de sentido que a palavra Geschwätz (tagarelar) possui em alguns textos de Benjamin. Já na "Metafísica da juventude" Benjamin produz uma diferença entre o tagarelar feminino, como vimos, e a verborragia (Wortfülle) do homem tagarela (Schwätzer). A verborragia com a qual Benjamin caracteriza a linguagem masculina pode ser pensada em analogia com a vacuidade (Wortleerheit) com a qual é caracterizada a linguagem humana no momento de seu surgimento, no célebre ensaio escrito como uma carta a Gerschom Scholem, e não originalmente destinado à publicação, "Sobre a linguagem em geral e sobre a linguagem humana", de 1916. Inclusive, nesse ensaio, escrito três anos após a "Metafísica da Juventude", a tipologia linguagem feminina/linguagem masculina parece ser retomada em outros termos, os de Medium e Mittel da linguagem, em uma releitura do Gênesis bíblico, como veremos agora.

Neste ensaio, Benjamin concebe a linguagem de uma maneira bastante abrangente. Essa abrangência pode ser assinalada pelo próprio termo alemão, "Sprache", que significa tanto língua quanto linguagem. Se em língua portuguesa temos uma divisão terciária entre "linguagem", "língua" e "discurso", 
em língua alemã há uma divisão binária entre "Sprache" (que significa tanto "linguagem" quanto "língua") e "Rede" ("discurso"). A indistinção entre "linguagem" e "língua", que o termo alemão "Sprache" denota, aponta para a possibilidade de existência tanto de uma língua/linguagem das coisas ou da natureza, quanto para a existência de uma língua/linguagem humana. Ou seja, a própria palavra alemã "Sprache" instiga a indagar sobre a possibilidade de existência de uma língua/linguagem não humana ou sobre uma "origem" da linguagem/língua em que o que está em questão não é meramente o caráter instrumental e comunicativo das diversas línguas históricas.

A propósito, é curioso notar que também em 1916, mesmo ano da escrita do ensaio de Benjamin acerca da linguagem, foi publicado, postumamente, o Curso de linguística geral, de quem veio a tornar-se o grande expoente da linguística moderna, Ferdinand Saussure. Logo na introdução do Cours, vê-se a diferença entre a concepção da linguagem benjaminiana e a concepção da linguística moderna. Primeiramente, porque Saussure produz uma distinção entre linguagem e língua, em que "a língua, assim delimitada no conjunto dos fatos de linguagem, é classificável entre os fatos humanos, enquanto que a linguagem não o é” (SAUSSURE, 2012, 47). A partir de tal distinção, a linguística saussuriana passa a ter por objeto a língua "como um sistema de signos que exprimem ideias" (SAUSSURE, 2012, 47), a semiologia.

Ao conceber a semiologia como "uma ciência que estuda a vida dos signos no seio da vida social" (SAUSURRE, 2012, 47), e ao afirmar que "o problema linguístico é, antes de tudo, semiológico" (SAUSSURE, 2012, 49), Saussure localiza a língua no âmbito da utilidade, como instrumento da comunicação, e na rede das práticas sociais. ${ }^{2} \mathrm{O}$ problema da linguagem resume-se, então, ao mero funcionamento da língua e ao seu caráter de representação. Ao contrário, para Benjamin, antes de ser instrumento da comunicação, a linguagem/língua comunica sua própria comunicabilidade, o fato mesmo de que ela existe: "a reposta à pergunta 'o que comunica a linguagem?' deve ser: 'toda linguagem comunica-se a si mesma'” (BENJAMIN,

\footnotetext{
2 Será nesse sentido que J.C. Milner dirá que a linguística, desde Saussure, tem em vista a realidade da língua, sua estrutura e funcionamento, e não o real da língua, para o qual a psicanálise apontaria. Cf. MILNER, O amor da língua. Campinas, SP: Editora Unicamp, 2012.
} 
2011d, p. 53). Por isso, de acordo com o exemplo que Benjamin fornece, quando falamos "lâmpada", essa palavra não comunica o objeto/significado "lâmpada", mas comunica "a lâmpada-linguagem", a "lâmpada-na-expressão" (BENJAMIN, 2011d, 53); ou seja, comunica a comunicabilidade da própria linguagem, o fato de que antes de comunicar qualquer coisa, a linguagem comunica sua própria existência, comunica a comunicabilidade de todo e qualquer comunicado e de todo e qualquer dito.

Nesse sentido, será por intermédio de uma releitura do Gênesis bíblico que Benjamin decomporá a linguagem em dois planos: o Medium da linguagem - a própria comunicabilidade da linguagem - e o meio (Mittel) da linguagem, o caráter instrumental da mesma. Ao Medium da linguagem corresponde a linguagem paradisíaca anterior à queda do paraíso, produzida no momento em que Adão prova do fruto proibido da árvore do conhecimento do bem e do mal. Essa linguagem, a linguagem com a qual deus teria criado o mundo, e da qual Adão participa ao nomear o mundo, é caracterizada como um meio em si mesma, ou seja, como uma comunicabilidade pura e simples, como a esfera na qual o que se comunica é a própria linguagem, o fato de que a linguagem é.

Assim, somente após o pecado cometido por Adão e Eva, ao provarem do fruto proibido, tem início a linguagem/língua humana, a linguagem/língua enquanto Mittel, enquanto meio para a comunicação de conteúdos exteriores à linguagem mesma. O momento do pecado contra a língua paradisíaca é também o momento de nascimento da linguagem/língua humana, instrumental, comunicativa, da linguagem judicante. Portanto, se ao Medium da linguagem corresponde, por um lado, a língua paradisíaca com a qual Adão nomeia o mundo, ou a comunicabilidade da própria linguagem, por outro lado, a linguagem humana coincide, em seu caráter instrumental - de ser um meio (Mittel) para um fim - com a queda do paraíso, no momento de provar do fruto proibido.

Assim, Benjamin dirá que "a árvore do conhecimento do bem e do mal não estava no jardim do Éden pelas informações que pudesse fornecer, mas como símbolo distintivo da sentença sobre aquele que pergunta" (2011d, 69). Para Benjamin, o momento de nascimento da palavra humana é também o momento de surgimento de uma culpa original, pois "a palavra que julga, pune 
seu próprio despertar como a única, a mais profunda culpa" (BENJAMIN, 2011d, 67). O termo em alemão para culpa é Schuld, que também significa dívida, "estar em débito". Nesse sentido, a palavra humana, o humano falante, ao falar, parece estar em débito com um vazio de significado, já que, como nos disse Benjamin, a árvore do conhecimento do bem e do mal não estava no Éden pelas informações que pudesse fornecer, mas sim como símbolo da sentença sobre aquele que pergunta.

A propósito, é interessante notar que Benjamin usa novamente a palavra tagarelar, “Geschwätż' para caracterizar essa relação de culpa ou débito (Schuld) e prevê, ainda, um dia do juízo final, um tribunal, para findar a relação de culpa que acomete o falante, o humano tagarela (Geschwätziger Mensch). Nas palavras de Benjamin:

o conhecimento do bem e do mal é [...] uma "tagarelice" [Geschwätz],
e este só conhece uma purificação e uma elevação (a que também foi
submetido o ser humano tagarela [Geschwätzige Mensch], o
pecador): o tribunal [...]. Essa palavra que julga expulsa os primeiros
seres humanos [die ersten Menschen] do paraíso; eles mesmos a
incitaram, em conformidade com uma lei eterna segundo a qual essa
palavra que julga pune seu próprio despertar como a única, a mais
profunda culpa [Schuld] - e é isso que ela espera (BENJAMIN, 2011d,
p. 67).

Aqui o tagarelar aparece remetido à impossibilidade do falante de dizer a dizibilidade da própria linguagem. Pois se a linguagem, como já nos dizia Platão, é sempre "legein ti kata tinos" (PLATÃO, 1972, p. 262a) dizer algo sobre algo, aquilo que permanece indizível nesse dizer é justamente a dizibilidade da própria linguagem. Por isso, o médium da linguagem aparece em uma dimensão negativa, de inefabilidade. Mas é justamente como contrapartida a essa relação de negatividade e inefabilidade que gostaria de pensar o tagarelar feminino, tal como concebido por Benjamin três anos antes. Gostaria de pensá-lo, então, como a possibilidade de dizer a dizibilidade da linguagem, para além de seu uso instrumental, hipótese possível se levarmos em conta o elemento do chiste em sua caracterização por Benjamin.

Pensar a linguagem para além de sua inefabilidade constitutiva, ou para além do fato de que ela já sempre antecipa o falante já sempre nela lançado, aparece como tarefa em uma carta de Benjamin a Martin Buber datada de 17

Doutoranda em Filosofia pela UFRJ. Brasileira, residente em Rio de Janeiro-RJ. E-mail: isabelafpinho@gmail.com 
de setembro de 1916, mesmo ano de redação de "Sobre a linguagem". Benjamin recusa o convite para participar da revista sionista "O judeu", ao afirmar que não concebe a linguagem como meio para o ato político, como mero instrumento, mas que tem em vista "a pura cristalina eliminação do indizível na linguagem [die kristallen reine elimination des Unsagbaren in der Sprache]" (BENJAMIN, 1979, 117). Voltarei a essa formulação mais adiante para pensar o que Lacan chama de efeito de cristal da língua. Por ora, gostaria de chamar atenção para algumas reformulações do Medium da linguagem tanto na "Tarefa do tradutor" (1921) quanto nas chamadas notas de Ibiza, de 1933.

Se, em "Sobre a linguagem", a língua pura, ou o Medium da linguagem, aparece como uma espécie de "origem" paradisíaca diante da qual o homem falante se encontra em uma relação de culpa ou débito, em "A tarefa do tradutor" ela aparece como aquilo que é visado (das Gemeinte) pelas múltiplas línguas históricas. Assim, as múltiplas línguas históricas teriam um parentesco supra-histórico justamente naquilo que visam e querem dizer: a pura língua. Mas o que me parece fundamental é o fato de que, ao fim do ensaio de Benjamin, a língua pura apareça caracterizada como uma palavra sem expressão (Ausdruckloses Wort), uma palavra que já não quer dizer nada e que já não exprime nada. Nas palavras de Benjamin:

\footnotetext{
Nessa pura língua, que já não quer dizer nada [nichts mehr meint] e já não exprime nada [nichts mehr ausdruckt], mas como palavra sem expressão e criadora é aquilo que é visado por todas as línguas, toda comunicação, todo sentido e toda intenção alcançam uma esfera em que estão destinados a se extinguir (BENJAMIN, 2011b, p.116). ${ }^{3}$
}

A tarefa do tradutor, assim como a do filósofo, é justamente a descrição e a exposição de uma língua livre de toda comunicação e de todo querer dizer, já que, se essa língua é o visado em cada língua histórica, ela, por outro lado, já não exprime nada e já não quer dizer mais nada. Nas duas notas sobre a linguagem que Benjamin escreve em Ibiza, em 1933 - "Sobre a faculdade mimética" e "A doutrina das semelhanças" - podemos dizer que o parentesco

\footnotetext{
${ }^{3}$ Tradução levemente modificada.
}

Doutoranda em Filosofia pela UFRJ. Brasileira, residente em Rio de Janeiro-RJ. E-mail: isabelafpinho@gmail.com 
supra-histórico das diferentes línguas históricas será pensado como da ordem das semelhanças extra-sensíveis (unsinnlicher Ähnlichkeiten). A linguagem será concebida como cânone, como registro das semelhanças não-sensíveis, em oposição a uma concepção da linguagem como mero sistema convencional e arbitrário de signos. Nas palavras de Benjamin, "a escrita transformou-se, ao lado da linguagem oral, num arquivo de semelhanças, de correspondências extrassensíveis" (2011a, 111). Esse arquivo material, poderíamos dizer, é constituído por homófonos, equívocos e mal-entendidos, cujo trecho "Mummerehlen" de Infância em Berlim, também escrito em 1933, pode bem elucidar. De fato, em carta a Scholem, Benjamin afirma que "A doutrina das semelhanças" foi escrita durante os estudos para aquele que deveria ter sido o primeiro capítulo de Infância em Berlim: a Mummerehlen. ${ }^{4}$

No trecho Mummerehlen Benjamin narra a experiência de ter ouvido pela primeira vez, quando criança, uma antiga rima sobre uma certa tia Rehlen, visto que Muhme é uma palavra obsoleta para tia. Mais precisamente, Muhme significa "a irmã da mãe", e de uma maneira geral, a ancestral, a parente mais velha da linha materna. Isso é importante, pois não me parece arbitrário que essa experiência com a linguagem seja marcada por uma experiência referente ao feminino, já que se trata aqui da tia matrilinear, e já que, um ano mais tarde, Benjamin escreve um artigo (1934-35) sobre o Matriarcado de Bachofen, autor com o qual ele havia tido contato desde 1916.

\footnotetext{
${ }^{4}$ Cf. Carta de fevereiro de 1933. SCHOLEM, G. Correspondências. Tradução de Neusa Soliz. São Paulo: Perspectiva, 1991, p. 45. A Infância em Berlim por volta de 1900, considerada pelo próprio Benjamin como um de seus sucessos no plano literário, não foi publicada em vida, mas somente alguns de seus fragmentos tiveram publicação na imprensa alemã entre 1933 e 1935. Trata-se de um conjunto de fragmentos de recordação da infância. Sua versão mais conhecida foi a organizada por Adorno e consiste na reunião, em livro, de uma série de fragmentos publicados nos jornais, e cujo fragmento inicial é o Tiergarten. A tradução brasileira produzida pela editora Brasiliense (Obras escolhidas, vol. II) segue a versão estabelecida por Adorno, que é a mesma das Obras Completas (Gesammelte Schriften) de Benjamin em língua alemã. Nos anos de 1980, no entanto, duas versões datilografadas e com correções manuscritas foram encontradas. Em 1981, Giorgio Agamben encontrou na Biblioteca Nacional da França um tapuscrito contendo uma dedicatória ao filho de Benjamin. Por fim, uma outra versão foi encontrada em 1988 na biblioteca da universidade de Giessen. Essa versão, conhecida como "Giessener Fassung" foi publicada na Alemanha somente em 2000 e representa o primeiro esboço do trabalho redigido entre 1932 e 1933. O primeiro capítulo dessa versão, contemporânea à escrita da "Doutrina das semelhanças", é o trecho Mummerehlen. Cf. LAVELLE, Patrícia. Religion et Histoire, sur le concept d'expérience chez Walter Benjamin. Paris: Les Éditions du Cerf, 2008. p.107.
} 
Em todo caso, ao narrar sua experiência infantil com a linguagem, Benjamin afirma que "os mal-entendidos [Missverständnisse] modificavam o mundo" (2011c, p. 111) para ele. Ele brinca, por exemplo, com o trocadilho kupferstich e kopffverstich e pois ao ouvir a palavra kupferstich, que significa "gravura de cobre", colocou-se debaixo de uma cadeira, esticou a cabeça para fora, ação denotada pela palavra alemã kopffverstich, e a isso chamou de "gravura de cobre". Sobretudo, Benjamin afirma que o dom de reconhecer semelhanças exercia-se nele por meio de palavras, mas não aquelas, como ele o diz, "que me faziam semelhante a modelos de civilidade, mas sim às casas, aos móveis, às roupas. E por isso ficava desorientado quando exigiam de mim semelhança" (BENJAMIN, 2011c, 93). É para essa experiência da linguagem como arquivo de semelhanças extrassensíveis na ordem das próprias palavras que a figura da Mummerehlen também aponta.

Benjamin, ao ouvir a expressão "Ich will dir was erzählen von der Mummerehlen [quero te contar algo sobre a tia Rehlen]" (BENJAMIN, 2011c, p. 94) rememora a sensação de assombro que a materialidade dos sons das palavras, sem significado algum, produzia. A Mummerehlen aparece como um espectro para escuta infantil e constitui de fato um arquivo de semelhanças sem sentido ou significado - se pudermos forçar a tradução de un-sinnlicher Änlichkeiten para semelhanças para além do sentido. ${ }^{5}$ Ela constitui, sobretudo, uma experiência de homofonia da própria língua, pois a partir da unidade dos sons entre Mummerehlen e Muhme Rehlen podemos ter acesso aos vários sentidos dessa palavra, para os quais gostaria rapidamente de apontar.

"Mumm" é o murmúrio de alguém que não quer ou não pode falar, o balbuciar da criança, enquanto que Mumme significa máscara ou o que é mascarado. No verbo mummen, essas duas significações se cruzam, pois "mumem corresponde à "mum mum sagen" ou à ação de murmurar, mas também àquela de se dissimular ou de se pôr sob uma máscara. Mummel é o nome de um lago na Floresta Negra e também de uma flor aquática, mas que, segundo Patrícia Lavelle no livro Religião e História, sobre o conceito de experiência em Walter Benjamin ainda nos reenvia à "forma mascarada

${ }^{5}$ A palavra alemã "Unsinn" pode significar tanto "sem sentido" quanto "extrassensível", "nãosensível". 
(vermummte Gestalt) dessa vez assustadora ou terrível (Schreckgestalt), como também a uma conversação secreta (heimliches reden)" (LAVELLE, 2008, 108-109). Chegaríamos assim à palavra Mummler, que significa sussurro, cochicho. Enfim, se são com todas essas variações de sentido que Benjamin parece jogar a partir da imagem da Mummerehlen, o importante para nós é o fato de que o médium da linguagem não mais é pensado em seu caráter de negatividade, de inefabilidade, mas aponta para uma experiência com a linguagem em que a própria dizibilidade da língua é dita, para além da intenção de um sujeito. E em Benjamin os homófonos seriam exemplo dessa autotransparência da língua em que aquilo que se diz é a dizibilidade mesma da língua.

Não será por acaso, portanto, que no chamado último ensino de Lacan (de 1970 em diante), o psicanalista trabalhará com o homófono la langue ("a língua") e lalangue ("alíngua"). Segundo Jean-Claude Milner, em $O$ amor da língua, la langue pertence à esfera da realidade da língua, ou seja, ao seu caráter instrumental, e lalangue aponta para o real da língua, registro inconsciente da linguagem, em que os equívocos, chistes e homófonos se dão. Não somente a "oposição" entre "alíngua" e "a língua" é extremamente próxima daquela entre Medium e Mittel da linguagem, como também, podemos dizer que até mesmo o percurso de Lacan é semelhante ao de Benjamin.

Seguindo indicações da psicanalista Geneviève Morel no livro $A$ lei da mãe, ensaio sobre o sintoma sexual, o primeiro ensino de Lacan marca a relação entre $o$ falante e a linguagem a partir da noção de uma falta constitutiva, um débito. Nesse primeiro ensino, Lacan, ainda muito influenciado pela linguística estruturalista e pela leitura de Kojève de Hegel, pensa o Nomedo-pai, releitura lacaniana do falo freudiano, como o primeiro significante que marca a "entrada" do falante na linguagem. O Nome-do-pai implicaria o falante em uma cadeia de significantes ("S1, S2, S3... Sn") em que o sujeito se encontraria em uma relação de falta, na medida em que o $S 1$, como significante que é pura marca do "assujeitamento" do sujeito à linguagem, é inacessível. ${ }^{6}$

\footnotetext{
${ }^{6}$ Nas palavras de Jacques-Alain Miller, nas célebres "Conferências caraquenhas": "a tese de Lacan é que o significado é um efeito do significante, e que os efeitos de significado são Doutoranda em Filosofia pela UFRJ. Brasileira, residente em Rio de Janeiro-RJ. E-mail: 
O registro do Real, em oposição aos registros do Simbólico e do Imaginário, ${ }^{7}$ aparece aqui, em sua negatividade, como resto, como aquilo que resta do encontro do falante com a linguagem. É para essa impossibilidade que a por vezes mal compreendida proposição lacaniana "não há relação sexual" aponta. "Não há relação sexual" quer dizer que o falante, na medida em que fala, é constitutivamente marcado por uma fratura, uma falta constitutiva, uma negatividade. Pois, se desde Aristóteles, o humano é definido como o zôon échon lógon, "o vivente que possui linguagem", aquilo de que ele não pode fazer a experiência na medida em que fala, na medida em que faz um uso instrumental da língua, é aquilo que constitui sua própria definição como humano e o diferencia do animal. Essa dimensão da existência da própria linguagem para além de seu caráter instrumental e comunicativo é chamada por Benjamin de Medium da linguagem, como vimos.

Por isso, podemos dizer que tanto em Benjamin como em Lacan, em determinado momento, a relação de negatividade entre o falante e a linguagem é acentuada. Porém, também em Lacan, há uma tentativa de repensar essa relação - ou de lidar com ela de um outro modo - que passa pelo feminino. Minha hipótese é de que o mesmo ocorra em Benjamin quando ele se propõe a investigar o que seria uma linguagem feminina no ensaio "Metafísica da Juventude". A partir de 1970, Lacan se afasta do estruturalismo e se aproxima cada vez mais da literatura, sobretudo da literatura de James Joyce, para quem dedica O seminário 23, O sintoma, e o escrito Joyce, le Symptôme. Essa mudança implica um afastamento do Nome-do-pai como o que marca o

criados pelas permutações, os jogos do significante. O sentido surge, fundamentalmente, da substituição de um significante por outro". MILLER, J.-A. Percurso de Lacan: uma introdução. Tradução de Ari Roitman. Rio de Janeiro: Jorge Zahar, 1988, p. 31. É da substituição do primeiro significante (S1), o Nome-do-pai, com referência a um significante S2, que advém o sentido ou o significado. Mas esse primeiro significante, do ponto de vista do sentido, é inacessível, por isso seu efeito de "pouco sentido" (peu de sens), como diz Lacan. Nas palavras de Lacan: "este 1 [S1] como tal, enquanto marca da diferença pura, é a ele que vamos nos referir para colocar à prova [...] as relações do sujeito com o significante. Teremos [...] que mostrar em que sentido o passo que é franqueado é aquele da coisa apagada; os diversos apagamentos[effaçons] [...] pelos quais o significante vem à luz, nos darão precisamente os modos capitais da manifestação do sujeito". LACAN, J. Seminário IX, A identificação (1961, 61). Tradução de Ivan Corrêia e Marcos Bagno. Recife: Centro de estudos freudianos do Recife, 2003, p. 64.

7 Real, Simbólico e Imaginário são os três registros universais que compõem a subjetivação em Lacan. O registro do Simbólico corresponde à linguagem, à palavra, ao significante; o do Imaginário, ao corpo próprio, às imagens e ao sentido; e o do Real, ao gozo. 
encontro entre o falante e a linguagem, e uma aproximação com o que ele chama de "falas impostas" (paroles imposées) d’alíngua materna. É também uma tentativa de pensar o registro do Real não mais como negatividade. Agora, seriam "as palavras impostas" recebidas pela criança através da língua materna que marcariam a relação entre o falante e a linguagem.

Para Lacan, não é arbitrário que alíngua seja materna, e isso quer dizer, que ela tenha relação com o feminino. Em "À Escola Freudiana", Lacan afirma que a mãe, diante da qual se encontra o bebê em sua "lalação", seu balbuciar, é exatamente a mesma coisa que alíngua, na medida em que ela é alíngua incarnada e que, como tal, a transmite ao bebê. ${ }^{8}$ Essa parece ser a mesma experiência infantil de linguagem descrita por Benjamin em Mummerehlen, palavra que - como vimos - em suas variações de sentido, contém tanto a Mumme matrilinear quanto o balbuciar (Mummler) e o murmurar (Mum mum sagen). Em todo caso, essa relação entre o falante e a linguagem, marcada pelos equívocos das palavras impostas d'alíngua materna, produziria sintomas no sujeito (symptômes com " $p$ ") a partir do quais, no trabalho de análise e no savor-y-faire, no saber-fazer com os sintomas, em uma outra lida com eles, 0 sujeito produziria o que Lacan chama de sinthome, com "th", no fim de análise. ${ }^{9}$

Assim, se o Nome-do-pai insere o sujeito em uma cadeia sucessiva de significantes, que também aponta para uma interpretação infinita no trabalho do analista, o que está em questão n'alíngua materna é a simultaneidade cujo exemplo é a homofonia. E se Benjamin definia o Medium da linguagem em

8 Cf. LACAN, Jacques. Alla Scuola Freudiana. Lacan in Italia, 1953-1978. Milão: La Salamandra, 1978, p. 104-147.

${ }^{9}$ Nas palavras de Geneviève Morel "a teoria do sinthoma propõe uma alternativa ao Nome-dopai", e isso não somente para psicóticos, como teria sido o caso de James Joyce. Assim, a relação entre linguagem e corpo, segundo Morel, pode passar ou não pelo Nome-do-pai, e ele também se torna um significante contingente. Como afirma Morel: "dizer que não existe nomeação unívoca do Real pelo Simbólico leva a refutar radicalmente a afirmação segundo a qual a sexuação de um sujeito seria fixada de uma vez por todas pelo Nome-do-pai. E, no entanto, alguns psicanalistas lacanianos sustentam esta tese com sua correlata de que a sexuação não seria jamais estabelecida na psicose visto que o Nome-do-pai não funciona aí. [...] A sexuação não provém de uma nomeação unívoca pelo Nome-do-pai - teoria simplista frequentemente promovida por razões ideológicas". Para Morel, há um importante elemento ético-político a ser levado em consideração na clínica da psicanálise implicado na virada do Nome-do-pai em direção às palavras impostas d'alíngua materna, na medida em que caberá a cada um, singularmente, interpretá-las; interpretação e criação que "colorem de ambiguidade a 'escolha' de uma identidade sexual". Cf. MOREL, Geneviève. La loi de la mère. Essai sur le sinthome sexuel. Paris: Ed. Economica, 2008, p. 327 - 331. 
1933 como o arquivo das semelhanças não-sensíveis, Lacan afirma que alíngua (lalangue) é "o depósito, a aluvião, a petrificação do inconsciente, e da maneira como um grupo lida com sua própria experiência" (LACAN, 2002, 9). A homofonia não aponta, portanto, para uma relação, mas sim para uma simultaneidade e imediatidade de aspectos materiais da própria língua, ou da dizizibilidade da língua mesma, para a qual Lacan constrói o neologismo "móterialisme", a materialidade (matérialisme) das próprias palavras (mots). Na homofonia, não há nada de indizível por dizer, pois é a própria dizibilidade da linguagem que se diz. Dessa maneira, a cristalina eliminação do indizível na linguagem, proposta por Benjamin, pode ser pensada nesse sentido. E de fato, em Radiofonia, Lacan não cansa de ressaltar "o caráter de cristal da língua" ou o "efeito de cristal homofônico" (LACAN, 2001, 425-427). De Benjamin a Lacan, o cristal da língua é o âmbito da dizibilidade da própria linguagem a partir de um ponto de vista material, o âmbito em que a oposição indizível/dizível não se dá.

Assim, se Benjamin, na "Tarefa do Tradutor", concebe o Medium da linguagem como aquilo que constitui o parentesco supra-histórico das línguas históricas, e, por isso, as ultrapassa, Milner dirá que é justamente dessa ultrapassagem que se trata na homofonia (crossover). ${ }^{10}$ Nesse sentido, Lacan aponta para a não arbitrariedade dos homófonos "une bévue", (em francês, uma mancada/ "que mancada!") e "Unbewusst" (em alemão, inconsciente). Do ponto de vista da materialidade das palavras, há uma relação não arbitrária entre "o inconsciente" (Unbewusst) e o chiste (bévue); o que agora nos faz retomar a questão do tagarelar feminino e de sua wahnwitzigen Sprache, de sua língua louca, na "Metafísica da juventude".

Muito curiosamente, também em Lacan, há um tagarelar feminino, e ele aparece em uma paródia que ele faz, para nossa surpresa, do Gênesis bíblico. Logo nas primeiras páginas do seminário 23 Lacan dirá que se Adão nomeou o mundo, é Eva quem primeiro se utilizou dessa linguagem, ao falar com a serpente. Em suas palavras:

10 Jean-Claude Milner usou a palavra "crossover" para pensar a relação de homofonia entre diversas línguas históricas na palestra "Back and forth form letter to homophony", no encontro Language and the intersection of Politics, Law and Desire, que ocorreu na Birbeck College, University of London em 25/04/2017, e do qual participei como ouvinte.

Doutoranda em Filosofia pela UFRJ. Brasileira, residente em Rio de Janeiro-RJ. E-mail: 
Adão, como seu nome pronunciado em inglês bem indica (...) era uma madame, de acordo com a piada que faz Joyce. ${ }^{11}$ É bem preciso supor que Adão nomeou as criaturas na língua daquela que chamaria de Évida. ${ }^{12}$. Posso chamá-la assim pois que em hebreu (...) seu nome quer dizer a mãe dos viventes. Bom, Évida tagarelou imediatamente nessa língua, pois após a suposta nomeação de Adão, a primeira pessoa que se serviu dela, foi ela, para falar com a serpente. A chamada criação divina se duplica no tagarelar do ser falante [parlote du parlêtre] (LACAN, 2005, p. 13).

Muitas páginas adiante, em uma passagem que ressoa a oposição entre linguagem masculina e linguagem feminina do ensaio de Benjamin de 1913, Lacan afirma que

o homem é o portador da ideia de significante. Essa ideia, em alíngua [lalangue] tem seu suporte essencialmente na sintaxe. De qualquer maneira, o que caracteriza alíngua entre todas são os equívocos [equivoce] que Ihe são possíveis, tal como ilustrei com equívoco de dois [deux] com deles [d'eux]. Se alguma coisa na história pode ser suposta, é que foi o conjunto de mulheres que engendrou o que chamei de alíngua (LACAN, 2005, p. 117).

Quando Lacan diz que a criação divina se duplica no tagarelar feminino do ser falante, ou quando diz que a ideia de significante, da qual o homem é portador, tem seu suporte em alíngua feminina, poderia parecer que, como suporte ou fundamento, o tagarelar feminino permanece em uma negatividade. Mas assim como, em psicanálise, o inconsciente não é um conceito negativo ou seja, não é aquilo que não vem à consciência, mas sim um pensamento que pensa e que diz, como afirma Lacan em "Meu ensino"13 - assim também alíngua, ao expor a dizibilidade e a expressividade da língua mesma, aponta para uma positividade. ${ }^{14}$

O que chamo aqui de positividade deve ser pensado como essa autotransparência da língua, marcada pelo caráter de imediatidade e sincronia

11 A piada consiste na proximidade dos sons das palavras "Adam" e "madam" em língua inglesa.

12 Lacan brinca com a homofonia entre "Èvie" e "est vie", que significa "é vida".

${ }^{13}$ Cf. LACAN, Jacques. Meu ensino. Tradução de André Telles. Rio de Janeiro: Jorge Zahar ed., 2006.

${ }^{14}$ Nas palavras de Zizek, o real d'alíngua "é a positividade pura de ser sem nenhuma faltacomo Lacan repete inúmeras vezes nesses anos, rien ne manque dans le réel, não falta nada no real, a falta só é introduzida pelo Simbólico." ZIZEK, Slavoj. "O Real". Em defesa das causas perdidas. Tradução de Maria Beatriz de Medina. São Paulo: Boitempo, 2011.

Doutoranda em Filosofia pela UFRJ. Brasileira, residente em Rio de Janeiro-RJ. E-mail: isabelafpinho@gmail.com 
da homofonia, da qual Lacan acentua seu efeito de cristal. Por isso, se Benjamin procura, em 1913, por uma linguagem feminina, e a caracteriza como uma língua dos chistes, podemos, seguindo suas reformulações acerca do Medium da linguagem, aproximá-la de alíngua lacaniana, engendrada, como Lacan o diz, por um conjunto de mulheres. Tanto em Lacan quanto em Benjamin, a língua feminina é marcada por equívocos e chistes e é a língua na qual aquela cristalina eliminação do indizível na linguagem se dá. Em trabalho futuro, gostaria de pensar nas implicações ético-políticas para a qual um pensamento do feminino poderia remeter. Sobretudo, gostaria de levar a sério as inquirições de Benjamin acerca do que seria uma cultura ou uma linguagem feminina, e acredito que o ensino de Lacan possa nos ajudar nesse sentido.

\section{REFERÊNCIAS}

BENJAMIN, Walter. A doutrina das semelhanças. Tradução de Sergio Paulo Rouanet. São Paulo: ed. Brasiliense, 2011a, p. 111. (Obras escolhidas vol.I).

A Tarefa do tradutor. Escritos sobre mito linguagem. Tradução de Susana Kampff Lages. São Paulo: Editora 34, 2011b, pp. 101119.

Correspondances I (1910-1928). Tradução de Guy

Petitdemange. Paris: Éditions Aubier-Montaigne, 1979.

Metaphysic der Jugend. Gesammelte Schriften, Vol. II, 1. Frankfurt am Main: Suhrkamp Verlag, 1991, pp. $91-105$.

Mummerhelen, Infância em Berlim por volta de 1900. Tradução de Rubens Rodrigues Torres Filho e José C. M. Barbosa. São Paulo: Brasiliense, 2011c. pp. 120 - 122 (Obras escolhidas Vol. II).

Sobre a linguagem em geral e sobre a linguagem do homem. Escritos sobre mito linguagem. Tradução de Susana Kampff Lages. São Paulo: Editora 34, 2011d, pp. 212-156.

LACAN, Jacques. Conferência A terceira [1974]. Cadernos Lacan. Porto Alegre: APPOA, 2002. v. 2.

2005.

. Le Sinthome (Le séminaire 23). Paris: Édition du Seuil, 
2001, pp. $403-447$.

"Radiophonie", Autres Écrits. Paris: Éditions du Seuil,

KIRSCH, Sebastien. Das Reale der Perspektive. Der Barock, die Lacanische Psychoanalyse und das "Untote" in der Kultur. Berlim: Theater der Zeit, 2013.

LAVELLE, Patrícia. Religion et Histoire, sur le concept d'expérience chez Walter Benjamin. Paris: Les Éditions du Cerf, 2008.

MILNER, Jean-Claude. $O$ amor da língua. Campinas, SP: Editora Unicamp, 2012.

MOREL, Geneviève. La loi de la mère. Essai sur le sinthome sexuel. Paris: Ed. Economica, 2008.

OLIVEIRA, Cláudio. "Língua pura e alíngua: um encontro (im)possível entre Benjamin e Lacan" in:_Revista Trágica: estudos de filosofia da imanência, Rio de Janeiro, v. 9, $\mathrm{n}$ 2, 2016, p. 41 - 50. Disponível em: $<$ http://tragica.org/artigos/v9n2/oliveira.pdf $>$.

PLATÃO. O sofista. Tradução de Jorge Paleikat e João Cruz Costa. São Paulo: Abril Cultural, 1972.

SAUSSURE. Curso de linguística geral. São Paulo: Cultrix, 2012. 